\title{
Gestation length in Holstein cow depends on the number and sex of fetuses
}

\author{
Ryoung-Hoon Jeon, Gyu-Jin Rho* \\ Department of Theriogenology and Biotechnology, College of Veterinary Medicine, Gyeongsang National University, \\ Jinju 52828, Korea
}

\begin{abstract}
The traditional calculation of gestation length (GL) in Holstein cows relies solely on the insemination day and has a high error rate for actual calving dates. The present study was conducted to develop a more accurate method of estimating GL. Among 3,578 Holstein cows, the number of fetuses had a significant $(p<0.05)$ effect, with GLs of $282.4 \pm 2.5$ days for singletons and $276.0 \pm$ 1.6 days for twins. Within the singleton group, the GLs were $284.6 \pm 1.9$ days for males and $280.3 \pm 1.5$ days for females, a significant difference $(p<0.05)$. However, within the twin group, there was no difference in GLs among twin males, twin females, or twins of both sexes. Gestation was significantly shorter for singleton males born from June to August but significantly longer for twin males born in the May to June period $(p<0.05)$. Neither parity nor housing type was associated with any significant difference in GL. In order to predict the calving dates of Holstein cows accurately and improve their management, calculations should consider the number and sex of fetuses as well as the insemination season.
\end{abstract}

Keywords: Holstein, gestation length, singleton, twins, sex

*Corresponding author

\section{Gyu-Jin Rho}

Department of Theriogenology and Biotechnology, College of Veterinary Medicine, Gyeongsang National University, 501 Jinju-daero, Jinju 52828, Korea

Tel: $+82-55-772-2347$

Fax: +82-55-772-2349

E-mail: jinrho@gnu.ac.kr

\section{ORCID}

Ryoung-Hoon Jeon

https://orcid.org/0000-0003-3174-1197

Gyu-Jin Rho

https://orcid.org/0000-0002-6264-0017

Conflicts of Interest

The authors declare no conflicts of interest.

Received: June 25, 2019

Revised: September 24, 2019

Accepted: October 17, 2019

\section{Introduction}

Cows give birth after a gestation of around 280 days, and farmers use this basic fact to determine breeding plans for their cows [1]. As gestation length (GL) affects income on both dairy and breeding farms, it is important to calculate it accurately in order to maintain farm management efficiency and yield a profit $[2,3]$. Calving problems such as dystocia require rapid intervention to ensure the safe delivery of the fetus and health of the mother [4], and thus, inaccurate estimates of GL may result in missed opportunities for dystocia treatment and decreased reproduction efficiency $[1,4]$. However, the conventional method of calculating GL is based only on the insemination day and does not reflect other factors [5]. For this reason, the conventional method is not sufficiently reliable [1]. Moreover, access to or maintenance in an outdoor environment also affects the reproductive physiology of cattle $[3,6]$. Accordingly, it is necessary to calculate the expected GL for each breeding environment $[5,7]$. In addition, as breeding continuously attempts to improve cow's traits, knowledge of their reproductive physiology should also be continuously updated [5]. It is known that the GL of cows varies with the breed, the breeding bull, the use of embryo transfer, and the mother's reproductive history. However, researchers have reported varied results on the effect of these factors due to inconsistent study approaches [3,7]. Various studies have reported that GL depends on either the sex or the number of fetuses, but no study in Korea has reported thoroughly on the combined effects of sex and number of fetuses on GL [5,8-10]. In addition, twin fetuses, in particular, are known to increase the incidence of postpartum disorders that reduce reproductive performance, but the relationship between the GL and the sex of twin fetuses has not been fully described $[11,12]$.

The aim of the present study was to calculate the expected GL for each breeding situation, thereby improving breeding plans for Holstein cows. To achieve this aim, the difference in GL was analyzed among different groups of cows, including those who gave birth to different sexes and numbers of fetuses. Additionally, the parity of the mother, housing type, and calving month were also examined as factors affecting GL. 


\section{Materials and Methods}

\section{Animals and farms}

Data regarding GL in 3,578 Holstein cows that gave birth between 2007 and 2018 were acquired from 12 dairy farms located in Gyeongju-si, Gyeongsangbuk-do, South Korea. Each calving from a multi-parity individual was regarded as an independent datum. Every target farm in the study maintained at least 30 dairy cows. The housing types were classified as open or closed housing according to the presence of an outdoor pasture, and the type had not been changed during the study period.

\section{Insemination}

Artificial insemination (AI) using frozen semen was conducted for all individual cows in the present study. In order to determine the optimal AI time, reproductive indicators such as vaginal mucous discharge, swelling and reddening of the vulva, and mounting of other cows were visually observed. The standard AI method was applied twice at a $12 \mathrm{~h}$ interval, as previously reported [13].

\section{Calculation of gestation length and classification of groups}

To calculate GL, the final AI day was set to zero and the number of days until calving was recorded. Cases of abortion or stillbirth were excluded from the analysis. The cows were classified into singleton and twin groups, according to the number of calves produced. These two groups were further divided into singleton male, singleton female, twin male, twin female, and twins of both sexes groups.

\section{Statistical analysis}

The statistical significance of each influential factor with respect to calving outcome was examined. Analysis of variance was used to analyze the effects of number and sex of fetuses, parity, and calving month, while the $t$-test was used to analyze the effects of housing type. Analyses were performed using Prism 7 software (GraphPad Software, USA). The criterion for significance was $p<0.05$. GL was expressed as a mean \pm standard deviation value.

\section{Results}

Calf distribution and gestation length according to the number and sex of fetuses

The mean GL of all sampled Holstein cows was $282.2 \pm$ 2.8 days. The calves were singletons in $95.2 \%$ of cases and twins in $4.8 \%$ of cases. The singleton male and the singleton female groups had GLs of $284.6 \pm 1.9$ and $280.3 \pm 1.5$ days, respectively, indicating a significant difference with respect to sex $(p<0.05)$. The singleton male and singleton female calves accounted for $49.0 \%$ and $46.2 \%$ of all calving cases, respectively. The twin males, twin females, and twins of both sexes groups had GLs of $276.2 \pm 1.8,276.1 \pm 1.3$, and 275.6 \pm 1.5 days, respectively, with no significant differences among those groups. The twin males, twin females, and twins of both sexes groups accounted for $2.3 \%, 1.4 \%$, and $1.1 \%$, respectively, of all calving cases (Table 1).

\section{Gestation length according to parity}

The GL of the twin male group tended to increase, although not significantly, in cows with a parity of 5 or higher. The remaining groups also did not show any significant difference in GL according to parity (Fig. 1A). Cows of the 1st, 2nd, 3rd, 4th, 5th, 6th, and $7^{-}$parities accounted for $27.5 \%, 22.8 \%, 20.9 \%, 14.8 \%, 6.8 \%, 4.1 \%$, and $3.2 \%$, respectively, of the total population (Fig. 1B). Cows of the 1st, 2nd, 3 rd, and 4 th parities comprised over $86 \%$ of the study population. When a comparison was made within the same group, 1 st parity cows were used as the reference standard.

\section{Gestation length according to housing type}

The housing types were classified into open housing (4 farms) and closed housing ( 8 farms), depending on whether there was an outdoor pasture. The GLs were similar, irrespective of housing type, for cows with the same number and sexes of fetuses (Fig. 2).

\section{Gestation length according to calving month}

The GL was significantly lower for singleton males born in the June to August period (i.e., AI in September to November) than that for singleton males born from December to

Table 1. Distributions of gestation lengths in Holstein cows according to the number and sex of fetuses

\begin{tabular}{llcc}
\hline \hline Singleton & Calving & Gestation length (days) & No. (\%) of calving \\
& Male & $284.6 \pm 1.9^{\mathrm{a}}$ & $1,752(49.0)$ \\
& Female & $280.3 \pm 1.5^{\mathrm{b}}$ & $1,653(46.2)$ \\
\multirow{2}{*}{ Twin } & Subtotal & $282.5 \pm 2.5^{\mathrm{c}}$ & $3,405(95.2)$ \\
& Males & $276.2 \pm 1.8^{\mathrm{d}}$ & $82(2.3)$ \\
& Females & $276.1 \pm 1.3^{\mathrm{d}}$ & $51(1.4)$ \\
& Both sexes & $275.7 \pm 1.5^{\mathrm{d}}$ & $40(1.1)$ \\
Total & Subtotal & $276.0 \pm 1.6^{\mathrm{d}}$ & $173(4.8)$ \\
\hline
\end{tabular}

Gestation lengths are expressed as mean \pm standard deviation values. Significantly different values $(p<0.05)$ are expressed by different superscript letters. 
A

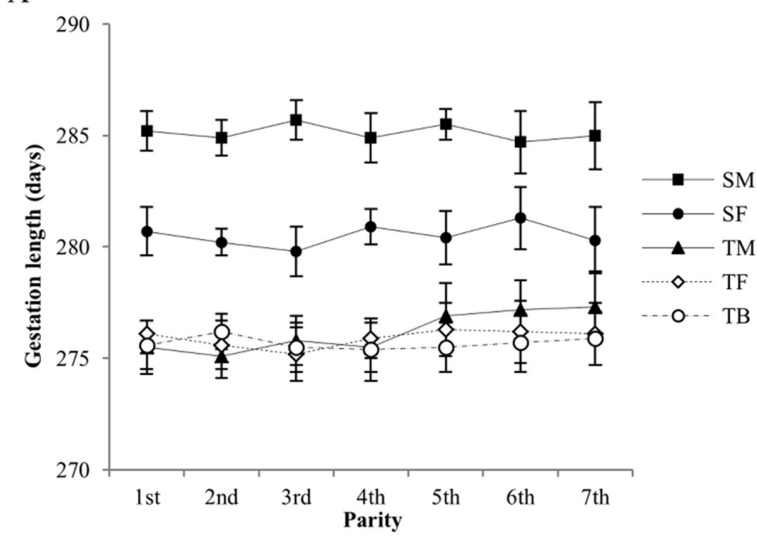

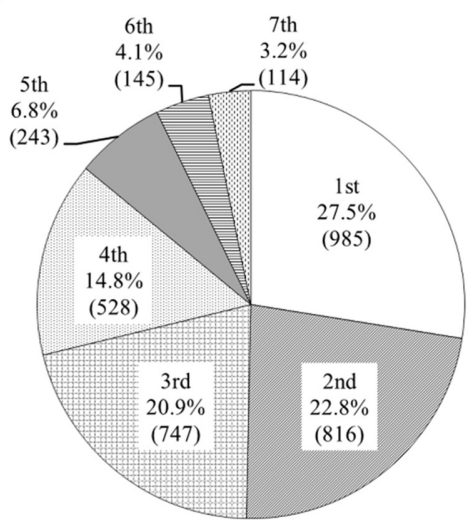

Fig. 1. Gestation lengths in Holstein cows, and types of calves born, according to parity. (A) Gestation length according to parity. (B) Percentage (number) of calving cases born to mothers of various parties. Values are means \pm standard deviation. SM, singleton male; $\mathrm{SF}$, singleton female; TM, twin males; TF, twin females; TB, twins of both sexes.

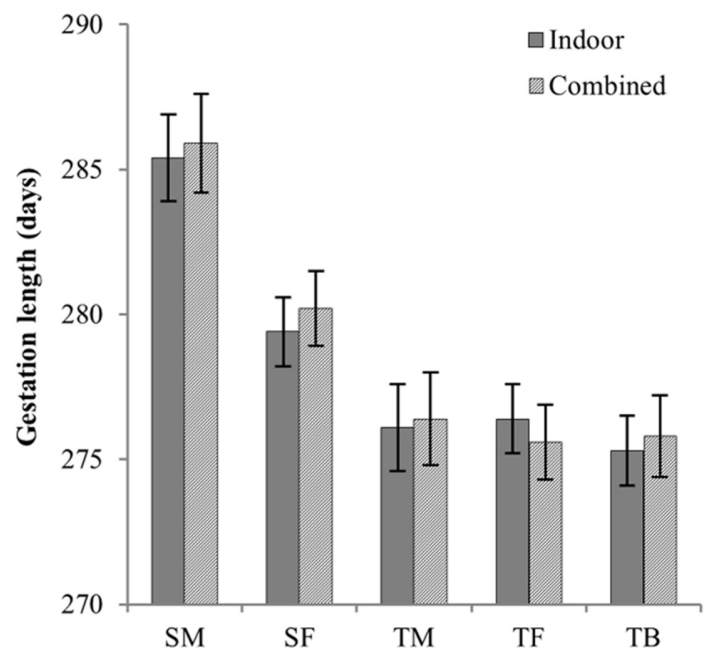

Fig. 2. Gestation lengths in Holstein cows according to housing type. Open housing and closed housing are distinguished according to the presence of an outdoor pasture. Values are means \pm standard deviation. SM, singleton male; SF, singleton female; TM, twin males; TF, twin females; TB, twins of both sexes.
March (i.e., AI in March to June) $(p<0.05)$. In the twin male group, the GL was significantly higher for calves born in the May to June period (AI in August to September) than for calves born in January, October, and December (AI in April, January, and March) $(p<0.05)$. In the remaining groups, there were no significant differences in GL with respect to calving month (Fig. 3).

\section{Discussion}

The present study sought to improve the accuracy of Holstein breeding schedules and help farms operate more efficiently by examining the differences in GL according to the number and sex of fetuses, parity, housing type, and calving month. The data showed that singleton calves had a longer gestation period than that of twins. Moreover, within the singleton group, males had a longer gestation period than that of females. Meanwhile, twins showed no significant difference in GL according to sex. Within the number and sex subgroups, there were slight differences in the GL of calves born during different months. However, maternal parity and hous-

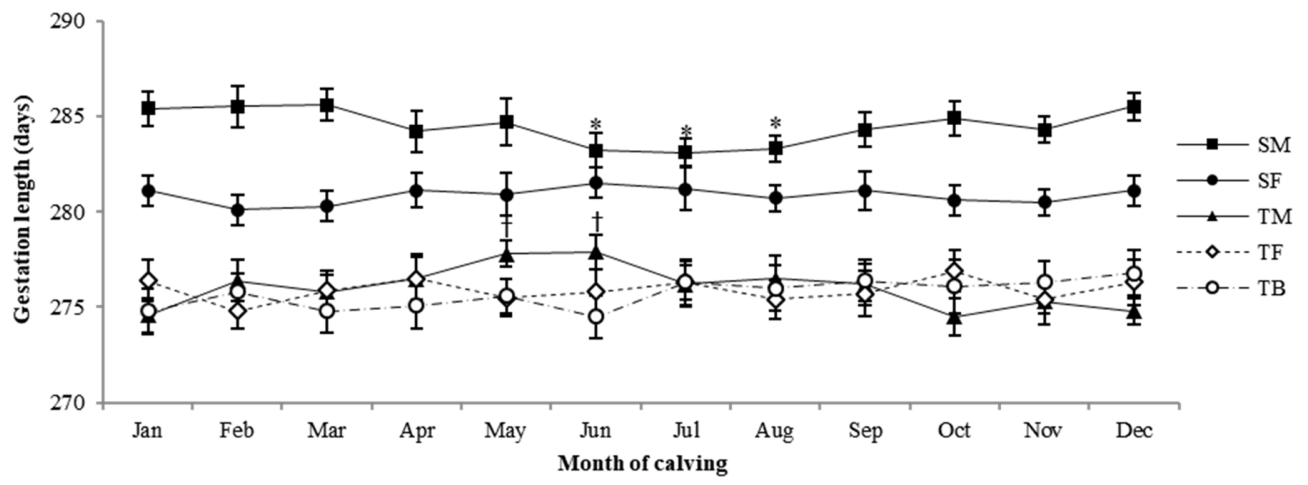

Fig. 3. Gestation lengths in Holstein cows according to calving month. Values are means \pm standard deviation. SM, singleton male; SF, singleton female; TM, twin males; TF, twin females; TB, twins of both sexes. ${ }^{*}$ "Designate significantly different values $(p<0.05)$ compared with other months within the SM and TM groups. 
ing type were not associated with any significant differences in GL. Based on these results, an appropriate calculation of the GL in Holstein cows should consider the number and sex of fetuses.

Reproduction in cows depends on their nutrition, the season, and the breeding environment [1,14]. After cows give birth, they are milked for colostrum for a short period and then used for commercial milk production. An accurate breeding schedule is very important because it enables a farm to maintain a relatively constant level of milk production $[5,13]$. Accurate calculation of GL can also reduce calving difficulty and improve fetal survival rate because it helps the farmer determine when calving is imminent and be ready to intervene, if necessary $[4,5]$.

The stages of reproduction in cows consist of estrus, insemination, gestation period, calving, and recovery. The gestation period occupies the largest portion of this sequence. Since the GL differs depending on the breed, usage of AI or embryo transfer, and breeding management, a method for the accurate calculation of GL is needed [2,3]. An appropriate approach that considers various factors simultaneously could be applied to diverse situations and prevent unnecessary confusion by prioritizing the information that has the greatest effect on GL $[6,7,14]$.

After implantation, a fetus grows through a continuous process involving metabolic, hormonal, and physical interactions with the mother and finally sends signals that trigger calving [15]. Thus, the fetus can influence GL. In the present study, the GL was significantly shorter for cows bearing twins than for those bearing singletons (Table 1). This has also been reported in previous studies, although they reported different GL $[12,16]$. As in previous studies, male singletons had a significantly longer gestation period than that of female singletons $[10,14,17]$. Interestingly, within the twin group, there was no significant difference in GL depending on the sex of fetuses (Table 1). This is the first time the relationship between GL and the sex of twin fetuses has been described in Korea.

However, the present study revealed that the GL depends primarily on the number and sex of fetuses, both of which influence the GL to different degrees (Table 1). Various factors such as nutrition, the particular breeding bull used, the use of embryo transfer, and breeding year have been suggested as factors affecting GL [6,9,14]. Unfortunately, the majority of existing studies have not considered such factors, rather they have applied data obtained on a uniform basis for their analyses, resulting in a remarkable variety of GL calculation results $[8,17]$. The number and sex of fetuses and the relative effects of various other factors need to be considered in order to increase the reproducibility of future GL studies.

Cows usually have multiple breeding cycles, and their parity affects not only their production capacity, such as milk production and the nutritional content of milk, but also, it affects their reproductive performance, including pregnancy rate, calving difficulty, and calf birth weight $[5,18,19]$. In the present study, parity was not associated with any significant change in GL (Fig. 1A). Gestation period tended to be shorter for cows with a parity of 5 and higher who gave birth to twin males. As the twin male group accounted for only $2.3 \%$ of total calving cases in this study, their data did not significantly influence the average GL for all cows (Fig. 1B). Due to the low proportion of twin male births, existing studies have paid little attention to this subset of cows $[8,17]$. However, the longevity of cows can affect farm income. Typically, livestock producers seek to continuously improve cow's traits and develop better feeding systems, as a result, longer-lived cows with high parity numbers may become more common [20]. Accordingly, although no relationship between parity and GL has been widely recognized previously, the relationship between decreasing GL and parity that was identified in the present study should be reassessed in larger-scale future studies. Results from such studies should help elucidate the reproductive physiology of high-parity cows.

Cows are affected by their breeding environment. Cows' reproductive performance, including estrus cycle, pregnancy rate, and days open (calving-to-conception interval), is affected not only by artificial factors, such as housing type and milking method, but also by natural factors, such as geographical location of farm, temperature, humidity, and the amount of sunshine in each season $[1,10,13]$. The present study distinguished the breeding environment according to artificial and natural factors and analyzed the effect of each factor on GL. Regarding artificial factors, the data showed that housing (open vs. closed) did not affect GL (Fig. 2). Accordingly, this factor may be excluded from future GL calculations [2].

Existing studies on the effect of calving month, a natural factor, on GL indicate that there are differences in GL according to the region and the climate. Gestation tends to be shortest in spring, followed by winter, autumn, and summer. In addition, when AI date was applied as the criterion, gestation was shorter for calves born in October than for those born in January and February. In other words, summer calving tended to be associated with a shorter gestation period $[1,10]$. The present study showed that the singleton male group had a shorter gestation period when calves were born in summer (Fig. 3). However, the twin male group had a longer gestation when calving occurred in the spring to summer seasons. The remaining groups did not display any variation in GL according to calving season (Fig. 3). As GL was affected in the singleton male and twin male groups according to the season, it is, therefore, necessary to include the number and sex of the fetuses in an accurate calculation of GL for these groups. The twin male group not only showed a GL tendency contrasting with previously reported results but also are particularly vulnerable to dystocia and postpartum disorders [11,12]. For this reason, additional studies are needed to identify the effect of AI and calving month on GL. As mentioned, parity, housing type, and calving month did 
not influence GL although they are directly related to various aspects of the reproductive cycle, including estrus, dystocia, and pregnancy rate. Accordingly, these factors need to be considered when determining an effective breeding schedule $[2,4,5,9]$.

The present study revealed that the number and sex of fetuses (but not a combination of sexes in twin fetuses) affect GL in Holstein cows. These results may help to solve the GL puzzle that many researchers and farmers have sought to solve. The results also showed that calving month has a partial influence on GL within the singleton male and twin males groups, but neither parity nor housing type was directly related to GL. The results of this detailed analysis clarify some of the essential factors that should be used when calculating GL, can help farms run more efficiently, and can improve understanding of the fundamental mechanisms that produce different GLs.

\section{References}

1. Norman HD, Wright JR, Kuhn MT, Hubbard SM, Cole JB, VanRaden PM. Genetic and environmental factors that affect gestation length in dairy cattle. J Dairy Sci 2009;92:22592269.

2. Lee DH, Lee WB, Kim JS, Lim JK, Yeo YK, Park YS. Effect of farm, cow parity, AI year and sire on gestation duration in Hanwoo. Korean J Anim Reprod 2001;25:231-235.

3. Choi BH, Jin JI, Kwon TH, Kim SS, Jo HT, Kong IK. Effect of recipient breeds on gestation length and birth weight of offspring derived from OPU Hanwoo embryos. Korean J Embryo Transf 2011;26:27-32.

4. Zaborski D, Grzesiak W, Szatkowska I, Dybus A, Muszynska M, Jedrzejczak M. Factors affecting dystocia in cattle. Reprod Domest Anim 2009;44:540-551.

5. Choy YH, Won JI, Yoon HB, Cho KH, Mahboob A, Cho C, Yeon SH, Park B, Yang B. Correlation among calf birth weight, calving difficulty and gestation length in a Korean Holstein dairy cattle herd. Ann Anim Resour Sci 2015;26:8589.

6. Shin WJ, Zheng ZY, Song JY, Ko YG, Shen XJ. Effects of environmental factors on gestation length and birth weight in Korean native and Yanbian yellow cows. Korean $\mathrm{J}$ Anim Reprod 1999;23:183-189.

7. Han KJ. Effects of environmental factors on reproductive traits in Korean cattle. J Anim Sci Technol 2002;44:191-200.
8. Hossein-Zadeh NG, Nejati-Javaremi A, Miraei-Ashtiani SR, Kohram H. An observational analysis of twin births, calf stillbirth, calf sex ratio, and abortion in Iranian Holsteins. J Dairy Sci 2008;91:4198-4205.

9. Park YS, Kim SS, Kim DH, Park HD. Effects of the in vitro produced Hanwoo blastocyst stage, in vitro culture day and blastocyst grade on the production of calves. Korean $\mathrm{J}$ Embryo Transf 2006;21:299-306.

10. Suk SH, Sel HS, Kwon EJ, Kim HJ, Jung YK, Song HB. Gestation lengths and offspring's birth weights and sex ratio of the dairy recipients transferred with Hanwoo IVF embryos. Korean J Embryo Transf 2009;24:15-19.

11. Echternkamp SE, Gregory KE. Effects of twinning on gestation length, retained placenta, and dystocia. J Anim Sci 1999;77: 39-47.

12. Kim IH, Kang HG. Effects of twin birth on the occurrence of postpartum disorders, culling and reproductive performance, and its risk factors in dairy cows. J Vet Clin 2011;28:339343.

13. Jeong GY, Park SJ, Kim NH, Baek KS, Jeon BS, Lim HJ, Her TY, Ki KS, Lee GS, Kang SY, Lee HJ, Chang WK, Kim HS. Factors effecting on artificial insemination in multiparturition cattle. Korean J Embryo Transf 2010;25:155-159.

14. Nogalski Z, Piwczyński D. Association of length of pregnancy with other reproductive traits in dairy cattle. Asian-Australas J Anim Sci 2012;25:22-27.

15. Kindahl H, Kornmatitsuk B, Königsson K, Gustafsson $H$. Endocrine changes in late bovine pregnancy with special emphasis on fetal well-being. Domest Anim Endocrinol 2002; 23:321-328.

16. Ryan DP, Boland MP. Frequency of twin births among Holstein-Friesian cows in a warm dry climate. Theriogenology 1991;36:1-10.

17. Silva del Río N, Stewart S, Rapnicki P, Chang YM, Fricke PM. An observational analysis of twin births, calf sex ratio, and calf mortality in Holstein dairy cattle. J Dairy Sci 2007; 90:1255-1264.

18. Kim GW, Kim JG. Changes of milk yield and compositions according to parity, milk yield and seasons in dairy cattle. Ann Anim Resour Sci 2017;28:1-8.

19. Fitzgerald AM, Ryan DP, Berry DP. Factors associated with the differential in actual gestational age and gestational age predicted from transrectal ultrasonography in pregnant dairy cows. Theriogenology 2015;84:358-364.

20. Do $\mathrm{CH}$, Cho JS, Cho KH, Yang BS, Yun HB, Lee JS. A study on the relationship between the longevity and profitability of dairy cattle. Korean J Agric Sci 2015;42:245-251. 